\title{
Manejo de irrigação para o feijão-de-metro, nas fases vegetativa e produtiva, em ambiente protegido ${ }^{1}$
}

\author{
Wellington G. da Silva ${ }^{2}$, Jacinto de A. Carvalho ${ }^{3}$, Eduardo C. Oliveira ${ }^{3}$, \\ Fátima C. Rezende ${ }^{3}$, Joaquim A. de Lima Junior ${ }^{4}$ \& Gervásio F. A. Rios ${ }^{3}$
}

\begin{abstract}
RESUMO
O manejo adequado da irrigação é uma prática agrícola que requer informações para cada cultura explorada, em particular nas fases fenológicas do ciclo produtivo pois muitas espécies possuem períodos críticos durante os quais o estresse hídrico causa sérias reduções na produção. Este trabalho teve, como objetivo, avaliar o efeito de cinco níveis de potencial matricial de água no solo sobre o crescimento e produção do feijão-de-metro. O experimento foi conduzido em casa de vegetação, na área experimental pertencente ao Departamento de Engenharia da Universidade Federal de Lavras, Lavras, MG. O delineamento experimental foi o de blocos casualizados, em esquema fatorial $5 \times 2$, com quatro repetições. Os tratamentos foram constituídos de cinco potenciais matriciais de água no solo como indicativos do momento de irrigar $(-15$, $-35,-55,-75$ e $-95 \mathrm{kPa}$ ), em duas fases fenológicas (vegetativa e produtiva), monitorados por sensores instalados a $0,15 \mathrm{~m}$ de profundidade. Os resultados permitiram concluir que a fase mais sensível ao déficit hídrico foi a produtiva e que a irrigação realizada no potencial matricial em torno de $-15 \mathrm{kPa}$ induziu a melhor resposta da cultura quanto ao desenvolvimento, produção e qualidade das vagens.
\end{abstract}

Palavras-chave: Vigna unguiculata spp. sesquipedalis, potencial matricial, crescimento

\section{Irrigation scheduling for asparagus bean in vegetative and productive stages in greenhouse}

\begin{abstract}
Proper irrigation water management requires knowledge on each exploited crop; particularly regarding vegetative and productive phases since many species have critical periods during which water stress causes serious yield reductions. This study was undertaken so as to assess the effect of five matric potential levels on asparagus bean growth and yield. The experiment was conducted under greenhouse conditions at the experimental area of Department of Engineering, Federal University of Lavras, Lavras, MG. The experimental design was randomized blocks in factorial $5 \times 2$. The treatments consisted of five matric potentials as indicative of the irrigation scheduling -15 - -35 -55 -75 -95 kPa and at two phenological stages (vegetative and reproductive) as monitored by sensors installed at $0.15 \mathrm{~m}$ depth. The results allowed to conclude that the most sensitive phase to water deficit was the productive, and that irrigation held at matric potential around $-15 \mathrm{kPa}$ led to better crop response in the development, production and quality of pods.
\end{abstract}

Key words: Vigna unguiculata spp. sesquipedalis, matric potential, growth

\footnotetext{
Parte da Tese de Doutorado do primeiro autor, apresentada à UFLA; Trabalho financiado pela FAPEAM e FAPEMIG

Engo Agrônomo, DSc./CED/UFAM, Av. Gen. R. O. J. Ramos, 3000, CEP 69077-000, Manaus, AM. E-mail: wellington1111@hotmail.com DEG/UFLA. C.P. 3037, CEP 37200-000, Lavras, MG. Fone: (35) 3829-1489. E-mail: jacintoc@deg.ufla.br; eduardoco@oi.com.br; frezende@deg.ufla.br; gervasiorios@yahoo.com.br

${ }^{4}$ DCEE/UFRA/Campus Paragominas,. E-mail: joaquim.junior@ufra.edu.br
} 


\section{INTRODUÇÃO}

A demanda crescente por hortaliças de qualidade aliada a problemas com escassez de terras cultiváveis próximas a grandes centros consumidores, precipitação excessiva ou insuficiente, racionalização do uso da água, problemas de salinização do solo e fitossanitários, além da globalização de mercado, fazem com que a produção agrícola se torne cada vez mais tecnificada para ser competitiva e atender ao mercado consumidor.

Devido a esses fatores tem-se buscado alternativas para assegurar a produção de um grande número de culturas agrícolas de interesse econômico e garantir oferta o ano todo, destacando-se entre elas a irrigação e o cultivo em ambiente protegido.

O manejo da irrigação representa os procedimentos utilizados para se irrigar. Para que esses procedimentos sejam realizados de forma correta é preciso não somente se ter meios que auxiliem na determinação do momento de irrigar e da quantidade de água a ser aplicada mas também conhecer a resposta das culturas aos procedimentos de manejo da irrigação adotados (Frizzone, 2007).

Informações sobre o efeito do manejo da irrigação para as culturas são importantes para: conhecer os períodos críticos durante os quais a deficiência de água causa sérias reduções à produção; determinar o momento de aplicar água de modo a maximizar a eficiência do seu uso, da energia elétrica, do sistema de irrigação e manter favoráveis as condições de umidade do solo para garantir a produção e o retorno dos investimentos.

Embora pareça óbvio que a produção de uma cultura aumente com a umidade do solo mantida próximo à capacidade de campo durante todo o seu ciclo produtivo, esta relação não se dá para todas as culturas ou mesmo fases fenológicas, conforme demonstram pesquisas realizadas com a cultura da cebola (Abreu et al.,1980), ervilha (Marouelli et al., 1991), berinjela (Bilibio et al., 2010) e outras. Os resultados das pesquisas realizadas por esses autores demonstram que recomendações generalistas dos procedimentos de manejo da irrigação para espécies do mesmo grupo agronômico, como hortaliças, por exemplo, são inadequadas, tendo em vista as respostas diferenciadas das espécies ao déficit hídrico.

O feijão-de-metro (Vigna unguiculata spp. sesquipedalis (L.) Verdc.) é uma hortaliça bastante cultivada no mundo. É originário da África Central (Sarutayopha et al., 2007) e teve seu cultivo estabelecido inicialmente no sudeste da Ásia (Ha et al., 2010). No Brasil esta cultura foi introduzida no Nordeste.
Após ser estabelecido disseminou-se por outras regiões do País, sobretudo para o Norte e Centro-oeste (Cardoso, 1997). Na região Norte seu consumo é expressivo, principalmente porque substitui a "vagem" em vários pratos (Silva, 2003).

A demanda da região Norte é atendida, de maneira especial, por pequenos produtores que têm, nesta hortaliça, uma fonte significativa de renda. No estado do Amazonas, onde o consumo é amplamente difundido, predominam os plantios realizados por agricultores da área de várzea (Cardoso, 1997).

Apesar de representar mais uma alternativa de renda para os produtores rurais do Amazonas, o feijão-de-metro ainda tem uma produção sazonal pois tanto o excesso de chuvas como a baixa umidade do solo são desfavoráveis ao seu cultivo; devido a isto sua oferta não atende à demanda do mercado regional durante todo o ano (Cardoso, 1997).

Diante da importância econômica e da escassez de informações para esta espécie, o trabalho foi realizado com o objetivo de se obter dados para o manejo da irrigação para a cultura, por meio da avaliação do efeito de cinco níveis de potencial matricial de água no solo sobre o desenvolvimento e produção da cultura

\section{Material e MÉTODOS}

O experimento foi realizado em casa de vegetação, na área experimental do Departamento de Engenharia da Universidade Federal de Lavras (UFLA), em Lavras, Minas Gerais. A área utilizada está localizada entre as coordenadas geográficas: $21^{\circ} 13^{\prime} 48^{\prime \prime}$ de latitude Sul, $44^{\circ} 58^{\prime} 36^{\prime \prime}$ de longitude Oeste e altitude de $902 \mathrm{~m}$. O solo foi classificado como Latossolo Vermelho Distroférrico (EMBRAPA, 2006); sua textura é argilosa para a camada de 0 a $30 \mathrm{~cm}$, cujas características físicas e químicas podem ser vistas na Tabela 1 . Durante a condução do experimento a temperatura e a umidade relativa média do ar foram de $27,5^{\circ} \mathrm{C}$ e $65,5 \%$, respectivamente.

A curva característica de retenção da água do solo foi obtida experimentalmente. Os valores obtidos foram ajustados ao modelo de Genuchten (1980). Com o auxílio do programa computacional SWRC 3.0 (Soil Water Retention Curve), desenvolvido por Dourado Neto et al. (2000), obteve-se a Eq. 1, com coeficiente de ajuste de 0,97:

$$
\theta=0,253+\frac{0,364}{\left[1+(0,2697|\psi|)^{2,0818}\right]^{0,5195}}
$$

Tabela 1. Características físicas e químicas do solo da área do experimento, para a camada de 0-30 cm de profundidade*

\begin{tabular}{|c|c|c|c|c|c|c|c|c|c|}
\hline \multicolumn{10}{|c|}{ Análise física } \\
\hline Areia & Silte & Argila & \multirow{2}{*}{\multicolumn{2}{|c|}{ Textura }} & $\rho_{\mathrm{g}}$ & \multicolumn{2}{|c|}{$\rho_{p}$} & $\theta_{\mathrm{cc}}$ & $\theta_{\mathrm{pm}}$ \\
\hline & $\left(\operatorname{dag~kg}{ }^{-1}\right)$ & & & & \multicolumn{3}{|c|}{$\left(\mathrm{g} \mathrm{cm}^{-3}\right)$} & \multicolumn{2}{|c|}{$(\%)$} \\
\hline 12,1 & 15,9 & 72,0 & \multicolumn{2}{|c|}{ Argilosa } & 1,01 & \multicolumn{2}{|c|}{2,64} & 0,42 & 0,27 \\
\hline \multicolumn{10}{|c|}{ Análise química } \\
\hline \multirow{2}{*}{$\begin{array}{c}\mathrm{pH} \\
\left(\mathrm{H}_{2} \mathrm{O}\right)\end{array}$} & \multirow{2}{*}{$\begin{array}{c}\text { MO } \\
\left(\mathrm{g} \mathrm{kg}^{-1}\right)\end{array}$} & $\mathbf{P}$ & K & $\mathrm{Ca}^{2+}$ & $\mathrm{Mg}^{2+}$ & V & $\mathrm{m}$ & B & $\mathrm{Zn}$ \\
\hline & & \multicolumn{2}{|c|}{$\left(\mathrm{mg} \mathrm{dm}^{-3}\right)$} & \multicolumn{2}{|c|}{$\left(\mathrm{cmol}_{\mathrm{c}} \mathrm{dm}^{-3}\right)$} & \multicolumn{2}{|c|}{ (\%) } & \multicolumn{2}{|c|}{$\left(\mathrm{mg} \mathrm{dm}^{-3}\right)$} \\
\hline 5,8 & 2,3 & 12,9 & 225 & 4,2 & 1,1 & 71,1 & 0,0 & 1,3 & 16,4 \\
\hline
\end{tabular}

$\mathrm{V}=$ Índice de saturação por bases, $\mathrm{m}=$ Índice de saturação por alumínio, $\rho_{\mathrm{g}}=$ densidade do solo, $\rho_{\mathrm{p}}=$ densidade das partículas, $\theta_{\mathrm{cc}}=$ umidade da capacidade de campo, $\theta_{\mathrm{pm}}=$ umidade a ponto de murcha, MO = matéria orgânica

"Análises realizadas no Laboratório de Física e Fertilidade do Solo do DCS/UFLA 
em que:

$\theta \quad$ - umidade do solo, $\mathrm{cm}^{3} \mathrm{~cm}^{-3}$

$\psi \quad$ - potencial de água no solo, $\mathrm{kPa}$

O delineamento experimental foi em blocos casualizados, com quatro repetições. Os tratamentos, dispostos num arranjo fatorial 5 x 2, resultaram na combinação de cinco níveis de potencial matricial $(-15,-35,-55,-75 \mathrm{e}-95 \mathrm{kPa})$, em duas fases de desenvolvimento da cultura (vegetativa e produtiva). Cada unidade experimental consistiu de um canteiro com uma linha de plantio de dois metros de comprimento e densidade de seis plantas por metro. Como úteis foram consideradas as 10 plantas centrais.

A fase vegetativa correspondeu ao período entre a emergência e a época em que $50 \%$ das flores das plantas do tratamento $-15 \mathrm{kPa}$ se encontravam abertas (50 dias após a emergência, DAE). Já a fase produtiva correspondeu ao período entre a antese e o final da colheita (82 DAE), quando as irrigações foram paralisadas.

Os canteiros foram delimitados internamente por um filme de polietileno preto (com espessura de $0,03 \mathrm{~mm}$ ), com o objetivo de impedir a movimentação de água entre eles e não interferir nos tratamentos. Os canteiros foram construídos com 2,0 m de comprimento, $0,40 \mathrm{~m}$ de largura e $0,30 \mathrm{~m}$ de profundidade no total de $240 \mathrm{dm}^{3}$, espaçados $0,40 \mathrm{~m}$ no sentido longitudinal e $0,60 \mathrm{~m}$ no sentido transversal. O solo utilizado nos canteiros foi seco ao ar, destorroado em peneira com $4 \mathrm{~mm}$ de malha, homogeneizado e levado de volta ao canteiro.

As adubações de plantio e de cobertura foram realizadas de acordo com a análise de fertilidade do solo e as recomendações para a cultura do feijão vagem (Carrijo et al., 1999). Foram utilizados $150 \mathrm{~kg} \mathrm{ha}^{-1}$ de $\mathrm{Ne} 280 \mathrm{~kg} \mathrm{ha}^{-1} \mathrm{de}_{2} \mathrm{O}_{5}$. A adubação de plantio foi feita durante o preparo do solo, adicionando-se todo o conteúdo de $\mathrm{P}_{2} \mathrm{O}_{5}$. Parte da adubação com $\mathrm{N}$ foi feita no dia da semeadura (30\%), e o restante $(70 \%)$ foi dividido em duas aplicações, realizadas aos 25 e 40 DAE. As fontes de nutrientes utilizadas foram ureia e superfosfato triplo.

A cultivar utilizada foi a "semente marron". Foram semeadas 36 sementes por canteiro, distribuídas em 12 sulcos de plantio a $1,0 \mathrm{~cm}$ de profundidade (1/10/2009). A germinação das sementes ocorreu em 05/10/2009 (quando 100\% das plântulas haviam emergido), data em que se iniciou a diferenciação dos tratamentos. Três dias após a emergência (08/10/2009) foi feito o desbaste deixando-se 12 plantas (conduzidas no sistema de espaldeira, com o último fio de arame a 1,8 $\mathrm{m}$ de altura em relação ao solo). Para garantir a germinação das sementes foram aplicados, no total, $75 \mathrm{~mm}$ de água em todos os tratamentos, parcelados em três irrigações de $25 \mathrm{~mm}$, em intervalos de um dia.

A irrigação foi realizada por gotejamento utilizando-se, em cada canteiro, seis gotejadores autocompensantes, espaçados $0,33 \mathrm{~m}$, com vazão de $4 \mathrm{Lh}^{-1}$ e pressão de serviço de $100 \mathrm{kPa}$. A uniformidade média de aplicação de água foi de $98,8 \%$, obtida logo após a montagem do sistema de irrigação.

O manejo da irrigação foi realizado com base no valor médio de leitura do potencial matricial observado nos sensores instalados em três unidades experimentais de cada tratamento (um por canteiro). Para monitorar os tratamentos com potencial matricial igual ou superior a -75 kPa utilizaram-se tensiômetros e sensores de matriz granular (Granular Matrix Sensor-GMS, Watermark $^{\circledR}$ ) no tratamento de $-95 \mathrm{kPa}$. As leituras foram realizadas diariamente (às 9, 12, 15 e 17 h) por meio de um tensímetro digital com sensibilidade de $0,1 \mathrm{kPa}$ e leitor digital do GMS.

No momento de cada irrigação os conteúdos volumétricos de água, associados às medidas de potencial matricial (na profundidade de $0,15 \mathrm{~m}$ ) foram utilizados para calcular a lâmina de irrigação a ser aplicada em cada tratamento visando elevar a umidade do solo à capacidade de campo (Tabela 1) até a profundidade de $0,30 \mathrm{~m}$.

A colheita das vagens foi feita durante 26 dias (57 a 82 DAE), sendo a mesma realizada 12 dias após a antese. Este critério foi baseado na observação de mudança de tonalidade na cor das vagens, quando passavam do verde escuro intenso para um verde claro brilhante, considerado o ponto ideal para colheita. Para padronizar tal procedimento diariamente, pela manhã, as flores que se encontravam abertas foram identificadas com fios de coloração diferente.

Os efeitos dos tratamentos foram avaliados sobre o diâmetro de colo, altura da parte aérea, massa seca de folhas, massa seca de ramos, massa seca total da parte aérea, massa fresca das vagens, comprimento das vagens, número de vagens por planta e produção da cultura.

O diâmetro de colo foi medido a $1 \mathrm{~cm}$ de altura em relação ao solo, utilizando-se um paquímetro digital e a altura do solo até a inserção da última folha do ramo principal, medida com uma trena metálica. Após tomadas as medidas as folhas foram separadas dos ramos e as plantas cortadas rente ao solo. Ambos, folhas e ramo, foram secados em estufa com circulação forçada de ar a $70{ }^{\circ} \mathrm{C}$, até obtenção de massa constante, para determinação da massa seca de folhas, massa seca de ramos e pelo somatório da massa seca de folhas e de ramos, a massa seca total da parte aérea. A altura das plantas foi obtida 50 DAE e o diâmetro de colo e a massa seca das plantas, 82 DAE. Todas as características de desenvolvimento e produção foram obtidas das 10 plantas centrais de cada canteiro.

Os dados coletados foram submetidos à análise de variância, análise de regressão e teste de Tukey para a comparação de médias. Na análise de regressão foram testados os modelos linear e polinomial de $2^{\circ}$ grau. As equações de regressão foram escolhidas com base na significância dos coeficientes de regressão, a 0,01 e 0,05 de probabilidade, pelo teste $\mathrm{F}$ e no maior valor do coeficiente de determinação $\left(\mathrm{R}^{2}\right)$. Os testes estatísticos foram realizados com o auxílio do programa estatístico SISVAR versão 5.0 (Ferreira, 2008).

\section{RESULTADOS E DISCUSSÃO}

Observa-se, na Tabela 2, que as lâminas aplicadas e o número de irrigações aumentaram com o aumento dos potenciais matriciais (solo com água mais facilmente disponível), o que era esperado. De acordo com Taiz \& Zeiger (2009), as plantas cultivadas em solo com água mais facilmente disponível apresentam maior desenvolvimento, área foliar e transpiração e, consequentemente, exigem irrigações mais frequentes e maior 
Tabela 2. Lâmina de água aplicada e número de irrigações realizadas no plantio e em cada fase fenológica do feijão-demetro sob diferentes níveis de potencial matricial $(\Psi)$

\begin{tabular}{|c|c|c|c|c|c|c|c|c|c|c|}
\hline \multirow{2}{*}{$\Psi(\mathrm{kPa})$} & \multicolumn{2}{|c|}{-15} & \multicolumn{2}{|c|}{-35} & \multicolumn{2}{|c|}{-55} & \multicolumn{2}{|c|}{-75} & \multicolumn{2}{|c|}{-95} \\
\hline & $L(m m)$ & $\mathbf{N}$ & $\mathrm{L}(\mathrm{mm})$ & $\mathbf{N}$ & $\mathrm{L}(\mathrm{mm})$ & & $\mathrm{L}(\mathrm{mm})$ & $\mathbf{N}$ & $\mathrm{L}(\mathrm{mm})$ & $\mathrm{N}$ \\
\hline Plantio & 75,0 & 3 & 75,0 & 3 & 75,0 & Plantio & 75,0 & 3 & 75,0 & 3 \\
\hline $\mathrm{FV}$ & 141,5 & 15 & 128,7 & 11 & 116,5 & FV & 141,5 & 15 & 128,7 & 11 \\
\hline FR & 150,9 & 16 & 145,2 & 12 & 126.9 & FR & 150,9 & 16 & 145,2 & 12 \\
\hline
\end{tabular}

FV - fase vegetativa; FR - fase produtiva; $L$ - lâmina de água; $N$ - número de irrigações

volume de água para repor o que foi utilizado para o metabolismo e também "cedido" para a atmosfera.

$\mathrm{Na}$ análise de variância (Tabela 3) observa-se efeito significativo do potencial matricial $(\Psi)$, das fases fenológicas (F) e da interação entre esses fatores para as variáveis diâmetro de colo (D), massa seca de folhas (MSF), massa seca de ramos (MSR) e massa seca total da parte aérea (MSPA) das plantas de feijão-de-metro, não sendo encontrado efeito significativo para altura $(\mathrm{p}>0,05)$. O comportamento de crescimento do feijão-de-metro em altura está compatível com o descrito por Oliveira (2009), que não verificou efeito significativo para a altura de plantas de pepino com a redução do potencial matricial $(-15,-30,-60$ e $-120 \mathrm{kPa})$ na fase vegetativa. Está coerente, também, com o obtido por Sá (2004) para o tomateiro irrigado com níveis decrescentes de potencial matricial (-15, -30, -50, $70,-120$ e $-170 \mathrm{kPa}$ ).

Como observado na Figura 1, as plantas que cresceram em solo mais úmido $(-15 \mathrm{kPa})$ na fase vegetativa apresentaram maior diâmetro de colo, massa seca de folhas, massa seca de ramos e massa seca da parte aérea que aquelas que se desenvolveram em solo mais seco (-35, -55, -75 e -95 kPa). Entretanto, sob essas mesmas condições de cultivo na fase produtiva as plantas apresentaram comportamento diferenciado para a massa seca de ramos em comparação com as demais variáveis de vez que, mesmo cultivada em solo mais seco, nesta fase o valor médio da massa seca de ramos permaneceu aproximadamente constante.

Uma provável explicação para este comportamento é o fato da maior parte dos ramos se ter desenvolvido ainda durante a fase vegetativa, quando as plantas eram irrigadas no maior potencial matricial (-15 kPa) e, como os ramos não sofrem abscisão sob condições ambientais desfavoráveis, ao contrário do que ocorre com as folhas (Taiz \& Zeiger, 2009), previa-se que a massa seca de ramos não fosse reduzida sob déficit hídrico na fase produtiva.

Tabela 3. Resumo da análise variância relativo ao diâmetro de colo (D), altura (AL), massa seca de folhas (MSF), massa seca de ramos (MSR) e massa seca total da parte aérea (MSPA) das plantas de feijão-de-metro sob diferentes níveis de potencial matricial $(\Psi)$ e fases fenológicas (F)

\begin{tabular}{|c|c|c|c|c|c|c|}
\hline \multirow{2}{*}{$\begin{array}{c}\text { Fontes de } \\
\text { variação }\end{array}$} & \multirow{2}{*}{ GL } & \multicolumn{5}{|c|}{ Quadrado médio } \\
\hline & & D & AL & MSF & MSR & MSPA \\
\hline$\Psi$ & 4 & $3,60^{*}$ & $2030,16 n s$ & $5538,15^{*}$ & $3098,20 *$ & $174,63^{*}$ \\
\hline $\mathrm{F}$ & 1 & $0,33^{*}$ & $1834,15 \mathrm{~ns}$ & $2468,83^{\star}$ & $17351,39 *$ & $6860,47^{*}$ \\
\hline$\Psi \times F$ & 4 & $0,19^{*}$ & $472,40 \mathrm{~ns}$ & $304,92^{*}$ & $3018,79 *$ & 1869,41 * \\
\hline Bloco & 3 & $0,08^{*}$ & $187,70 \mathrm{~ns}$ & $100,38^{*}$ & $1606,90 *$ & $1345,65^{*}$ \\
\hline Resíduo & 27 & 0,07 & 0,09 & 55,73 & 6378,13 & 517,82 \\
\hline CV (\%) & & 3,59 & 12,40 & 11,62 & 10,87 & 11,08 \\
\hline
\end{tabular}

As equações de regressão ajustadas indicam superioridade das plantas cultivadas sob regime de irrigação no maior potencial matricial $(-15 \mathrm{kPa})$. Esses resultados evidenciam que irrigações realizadas sob menores potenciais matriciais $(-35, \quad-55,-75$ e -95 $\mathrm{kPa}$ ) promovem inibição no crescimento e desenvolvimento,

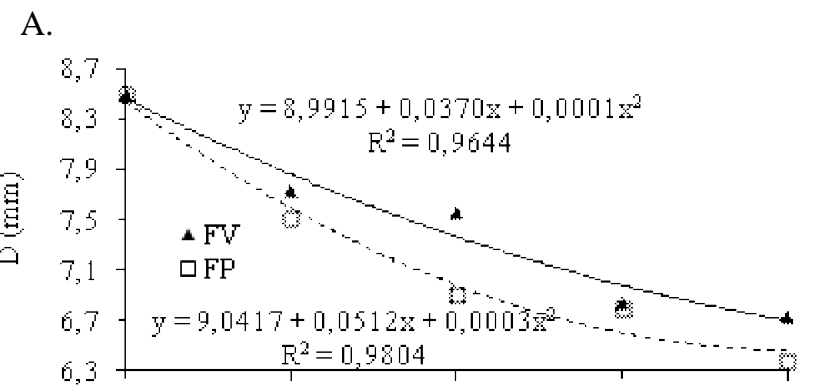

B.

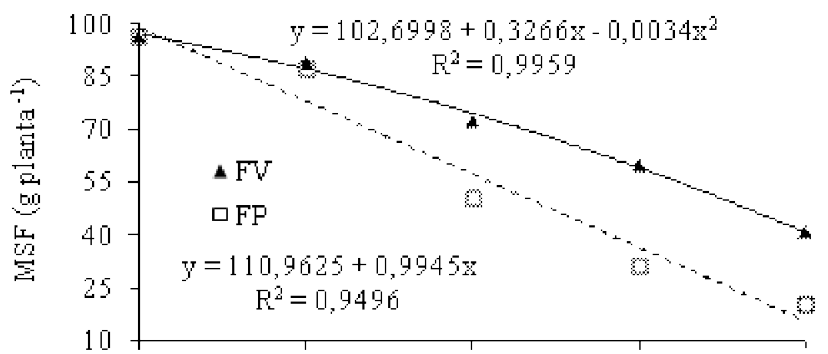

C.

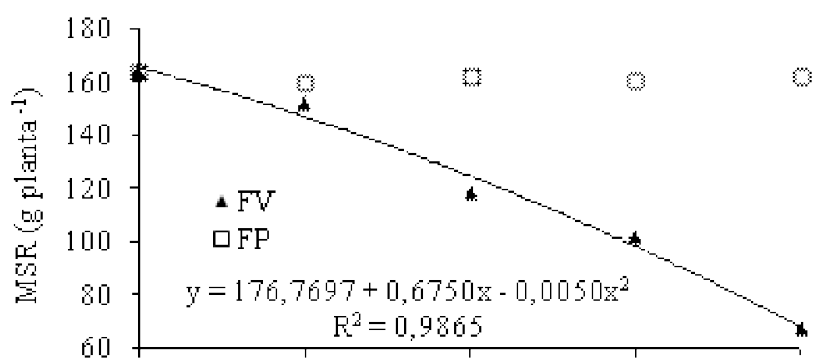

D.

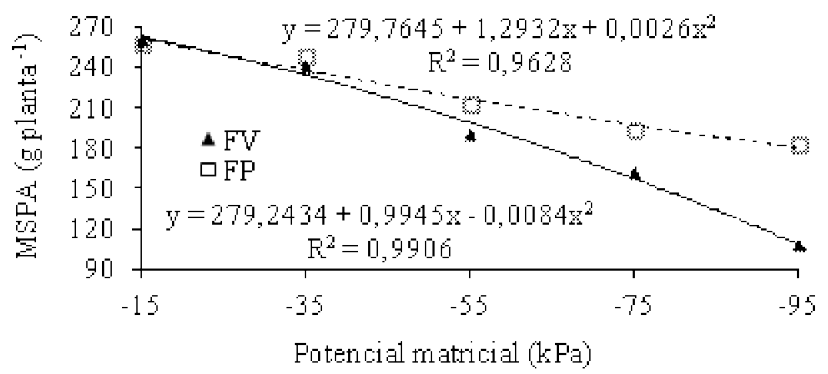

Figura 1. Diâmetro de colo - D (A), massa seca de folhas - MSF (B), massa seca de ramos - MSR (C) e massa seca da parte aérea - MSPA (D) do feijão-de-metro em função do potencial matricial nas duas fases fenológicas 
conforme observaram outros pesquisadores (Santos \& Pereira, 2004; Farias \& Saad, 2005; Macedo et al., 2010).

A tendência de redução de diâmetro de colo (Figura 1A), produção de massa seca de folhas (Figura 1B), massa seca de ramos (Figura 1C) e de massa seca total da parte aérea (Figura 1D) à medida em que reduz os potenciais matriciais, pode ser atribuída à dificuldade que as plantas de feijão-de-metro tiveram em absorver água pois numa situação de menor potencial matricial a água fica retida mais fortemente à superfície dos coloides; assim, as plantas precisam gastar mais energia para adquirir água para uso em seus processos fisiológicos vitais, fato que afeta negativamente as características de crescimento.

Os resultados obtidos nesta pesquisa concordam com os obtidos por Marouelli et al. (2003b), que constataram diminuição na produção de massa seca da parte aérea de plantas de alho quando as irrigações na fase vegetativa e produtiva eram realizadas a potenciais matriciais entre $-20 \mathrm{e}-160 \mathrm{kPa}$. O mesmo foi observado por Marouelli et al. (2003a) para o tomateiro irrigado na fase produtiva com potenciais matriciais entre -15 a $-70 \mathrm{kPa}$. Mencionados autores atribuíram tais resultados às adaptações das plantas ao déficit hídrico na fase vegetativa, como maior crescimento de raízes, menor índice de área foliar e maior espessura da cutícula da folha. As diferenças observadas para a resposta dessas espécies de plantas devem estar relacionadas aos níveis de potencial matricial empregados e à diferente sensibilidade de cada espécie ao déficit hídrico na fase fenológica do seu ciclo, reforçando a afirmativa de que cada espécie cultivada deve receber manejo de irrigação diferenciado e de acordo com suas necessidades.

Na Tabela 4 são mostrados os resultados do teste de médias para diâmetro de colo (D), massa seca de folhas (MSF), massa seca de ramos (MSR) e massa seca total da parte aérea (MSPA) do feijão-de-metro submetido ao manejo diferenciado de irrigação nas fases vegetativa (FV) e produtiva (FR) da cultura. Observase que o diâmetro de colo e a massa seca de folhas das plantas tiveram médias superiores quando as irrigações foram feitas nos níveis mais elevados de potencial matricial na fase vegetativa. Esses resultados sugerem que na fase produtiva as plantas foram mais sensíveis à redução dos níveis de umidade do solo em função do manejo diferenciado de irrigação nesta fase fenológica pois maiores valores de diâmetro de colo e massa seca de folhas indicam plantas mais robustas vegetativamente e com maior capacidade fotossintética (Pavani et al., 2009).

Observa, na Figura 1B, que a redução da massa seca de folhas das plantas irrigadas nos potenciais matriciais menores

Tabela 4. Teste de médias para diâmetro de colo (D), massa seca de folhas (MSF), massa seca de ramos (MSR) e massa seca total da parte aérea (MSPA) do feijão-demetro sob diferentes níveis de potencial matricial nas fases vegetativa (FV) e produtiva (FR)

\begin{tabular}{ccccc}
\hline \multirow{2}{*}{ Fase } & Diâmetro & MSF & MSR & MSPA \\
\cline { 3 - 5 } & $(\mathbf{m m})$ & & (g planta $\left.^{-1}\right)$ \\
FV & $7,47 \mathrm{a}$ & $71,73 \mathrm{a}$ & $120,64 \mathrm{~b}$ & $192,29 \mathrm{~b}$ \\
FR & $7,19 \mathrm{~b}$ & $56,27 \mathrm{~b}$ & $162,20 \mathrm{a}$ & $218,48 \mathrm{a}$ \\
\hline
\end{tabular}

Médias seguidas da mesma letra na vertical não diferem entre si a $5 \%$ de probabilidade pelo teste de Tukey nas duas fases fenológicas se deu de forma semelhante porém o mecanismo de adaptação utilizado sob essas condições de cultivo foi diferenciado. Enquanto na fase vegetativa a redução da massa seca de ramos se deu em função da emissão de menor número de folhas e redução da área das folhas em expansão, na fase produtiva a redução da massa seca de folhas ocorreu devido à queda das folhas já completamente expandidas, conforme observado durante a condução do experimento.

Maiores valores de massa seca da parte aérea indicam melhor desenvolvimento das plantas (Pavani et al., 2009); entretanto, conforme o resultado obtido nesta pesquisa, este parâmetro não foi indicativo adequado para caracterizar o crescimento das plantas de feijão-de-metro submetidas ao manejo diferenciado de irrigação. Percebe-se, na Tabela 4, que embora as plantas de feijão-de-metro tenham apresentado maior média de massa seca total da parte aérea quando as irrigações foram realizadas a valores mais elevados de potencial matricial na fase produtiva, elas apresentaram menor crescimento em diâmetro de colo, fato que reforça esta afirmativa.

Conforme a Tabela 4, a maior contribuição para a produção de massa seca total da parte aérea independente da fase em que as plantas foram irrigadas a potenciais matriciais menores o que se deveu à massa seca de ramos pois sua média foi maior do que a proporcionada pela massa seca de folhas; contudo, observase que a massa seca de folhas foi maior na fase vegetativa (Tabela 4). Isto reforça a afirmativa de que a massa seca de folhas foi a que mais contribuiu para o melhor desempenho das plantas ao se admitir que plantas com mais massa seca de folhas possuem maior lâmina foliar e, portanto, maior potencial para sintetizar os metabólitos essenciais ao crescimento, desenvolvimento e produção das culturas (Pavani et al., 2009).

A análise de variância (Tabela 5) indicou efeito significativo do potencial matricial $(\mathrm{Y})$, das fases fenológicas $(\mathrm{F})$ e da interação entre esses fatores para número de vagens $(\mathrm{NV})$, massa fresca de vagens (MFV), comprimento de vagens (CV) e produção de vagens $(\mathrm{PV})$.

Verifica-se, na Figura 2, que houve redução do número de vagens por planta e da produção de vagens sempre que a irrigação era realizada nos valores mais elevados de potencial matricial, independente da fase fenológica. No entanto, para massa fresca de vagens e comprimento de vagens somente foi observado este comportamento quando a diferenciação no manejo da irrigação foi realizada na fase produtiva.

Tabela 5. Resumo da análise de variância relativo ao número de vagens (NV), massa fresca de vagens (MFV), comprimento de vagens (CV) e produção de vagens (PV) de feijão-de-metro sob diferentes níveis de potencial matricial $(\Psi)$ e fases fenológicas $(F)$

\begin{tabular}{|c|c|c|c|c|c|}
\hline \multirow{2}{*}{$\begin{array}{c}\text { Fontes de } \\
\text { variação }\end{array}$} & \multirow{2}{*}{ GL } & \multicolumn{4}{|c|}{ Quadrado médio } \\
\hline & & NV & MFV & CV & PV \\
\hline$\Psi$ & 4 & $997,70^{*}$ & $2,93^{*}$ & $18,74^{*}$ & $179602,99^{*}$ \\
\hline $\mathrm{F}$ & 1 & $36,48^{*}$ & $39,20^{*}$ & $132,13^{*}$ & $100761,44^{*}$ \\
\hline$\Psi \times F$ & 4 & $3,74^{*}$ & $2,55^{*}$ & $11,69^{*}$ & $6032,65^{\star}$ \\
\hline Bloco & 3 & $0,87^{\star}$ & $0,13^{*}$ & $3,33^{*}$ & $873,95^{\star}$ \\
\hline Resíduo & 27 & 4,26 & 0,58 & 2,15 & 1810,67 \\
\hline CV (\%) & & 4,70 & 6,70 & 3,60 & 8,40 \\
\hline
\end{tabular}


A.

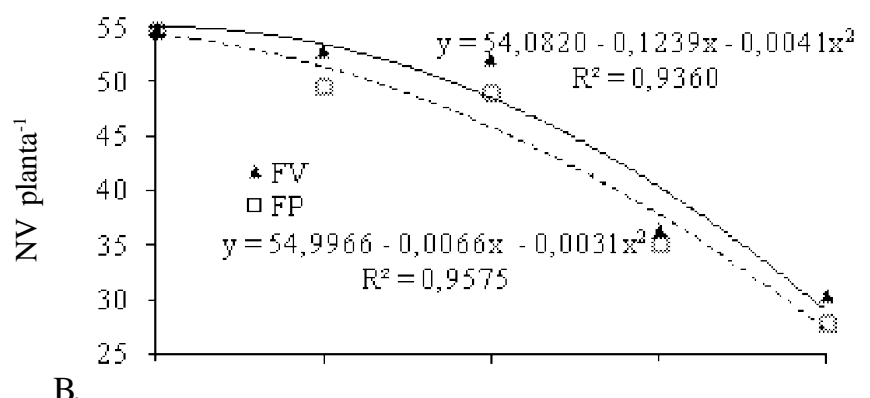

B.

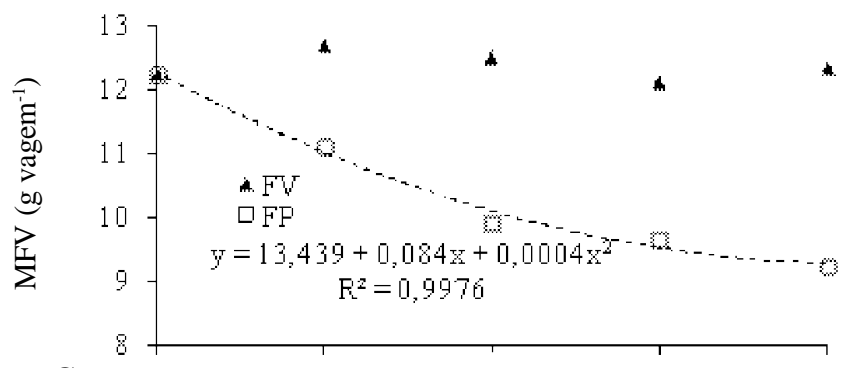

C.

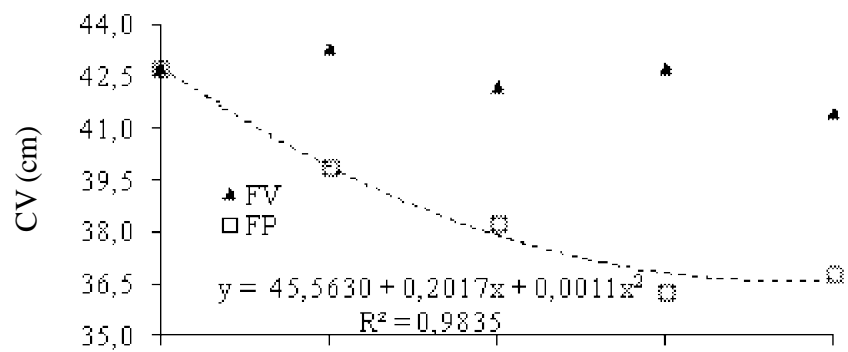

D.

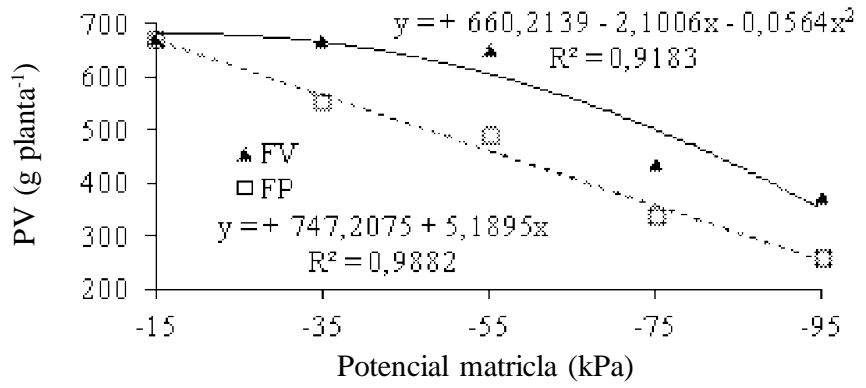

Figura 2. Número de vagens - NF (A), massa fresca de vagens - MFV (B), comprimento de vagens - CV (C) e produção de vagens - PV (D) das plantas de feijão-demetro em função do potencial matricial nas duas fases fenológicas (FV - fase vegetativa, FP - fase produtiva)

Pode-se inferir, a partir desses resultados, que as irrigações realizadas abaixo de $-15 \mathrm{kPa}$ na fase vegetativa influenciaram quantitativamente a produção, pela redução do número de vagens, ao passo que na fase produtiva, além de afetar a quantidade de vagens, afetou também a qualidade das vagens, pela redução da sua massa fresca.

Os maiores valores estimados para o número de vagens (Figura 2A), massa fresca de vagens (Figura 2B), comprimento de vagens (Figura 2C) e produção de vagens (Figura 2D) foram obtidos quando a irrigação foi realizada no potencial matricial $\mathrm{de}-15 \mathrm{kPa}$. Esses resultados sugerem que, para se obter maior produção e vagens de melhor qualidade, a irrigação do feijão- de-metro deve ser realizada com mais frequência e, portanto, estando o solo mais próximo da capacidade de campo.

O efeito do manejo da irrigação na fase produtiva foi mais pronunciado que aquele observado na fase vegetativa (Tabela 6), sugerindo que as irrigações realizadas sob valores menores de potencial matricial na fase produtiva foram mais prejudiciais à produção das plantas de feijão-de-metro.

Tabela 6. Teste de médias para número de vagens (NV), massa fresca de vagens (MFV), comprimento de vagens (CV) e produção de vagens (PV) do feijão-de-metro sob diferentes níveis de potencial matricial nas fases vegetativa (FV) e produtiva (FP)

\begin{tabular}{|c|c|c|c|c|}
\hline \multirow{2}{*}{ Fase } & \multirow{2}{*}{$\begin{array}{c}\text { NV } \\
(\text { um planta } \\
\text { (-1) }\end{array}$} & MFV & PV & \multirow{2}{*}{$\begin{array}{c}\text { CV } \\
\left(\mathrm{cm}^{2} \text { vagem }^{-1}\right)\end{array}$} \\
\hline & & \multicolumn{2}{|c|}{ (g planta $^{-1}$ ) } & \\
\hline FV & $45,00 \mathrm{a}$ & $12,38 \mathrm{a}$ & $559,91 \mathrm{a}$ & $42,48 a$ \\
\hline FP & $44,00 \mathrm{~b}$ & $10,39 \mathrm{~b}$ & $459,53 \mathrm{~b}$ & $38,84 \mathrm{~b}$ \\
\hline
\end{tabular}

Médias seguidas da mesma letra na vertical não diferem entre si a 0,05 de probabilidade pelo teste de Tukey

Nos ecossistemas naturais e cultivados a atividade fotossintética das plantas resulta na conversão da energia solar em energia química, a qual é essencial para a produção vegetal (Taiz \& Zeiger, 2009). Como a produção da planta é dependente da fotossíntese pode-se inferir que a superioridade de rendimento obtida pelas plantas irrigadas com déficit hídrico na fase vegetativa foi atingida devido ao seu maior potencial de produção de fotoassimilados pois possivelmente houve maior interceptação de radiação solar pelas folhas em função da maior produção de folhas (Tabela 4).

\section{CONCLUSÕES}

1. Independente da fase fenológica, o maior desenvolvimento de planta, produção e qualidade de vagens, foram observados nos tratamentos irrigados com potencial matricial de $-15 \mathrm{kPa}$, medido a $0,15 \mathrm{~m}$ de profundidade.

2. A fase fenológica do feijão-de-metro mais sensível às irrigações com maior déficit hídrico (-30, -55, - 75 e - $95 \mathrm{kPa}$ ) foi a produtiva na qual o rendimento e a qualidade das vagens foram menores que na fase vegetativa.

\section{Agradecimentos}

À Fundação de Amparo à Pesquisa do Estado do Amazonas (FAPEAM), pela concessão da Bolsa de Auxílio; À Fundação de Amparo à Pesquisa do Estado de Minas Gerais (FAPEMIG), pelo financiamento do projeto e ao Departamento de Engenharia da UFLA, pela oportunidade de capacitação.

\section{LITERATURA CITADA}

Abreu, T. A. S.; Silveira, P. S.; Pereira, G. T. Análise da produção de cebola sob diferentes regimes de irrigação. Pesquisa Agropecuária Brasileira, v.15, p.233-236, 1980. 
Bilibio, C.; Carvalho, J. A.; Martins, M.; Rezende, F. C.; Freitas, E. A.; Gomes, L. A. A. Desenvolvimento vegetativo e produtivo da berinjela submetida a diferentes tensões de água no solo. Revista Brasileira de Engenharia Agrícola e Ambiental, v.14, p.730-735, 2010.

Cardoso, M. O. Hortaliças não-convencionais da Amazônia. Manaus: Embrapa CPAA. 1. ed. Brasília: Embrapa SPI, 1997. $152 \mathrm{p}$.

Carrijo, I. V.; Filgueira, F. A. R.; Trani, P. E. Feijão-Vagem (Trepador). In: Ribeiro, A. C.; Guimarães, P. T. G.; Alvarez V. V. H. (ed.). Recomendações para uso de corretivos e fertilizantes em Minas Gerais. 5.ed. Lavras: CFSEMG, 1999. $359 \mathrm{p}$.

Dourado Neto, D.; Nielsen, D. R.; Hopmans, J. W.; Reichardt, K.; Bacchi, O. O. S. Software to model soil water retention curves (SWRC, version 2.00). Scientia Agricola, v.57, p.191192, 2000.

EMBRAPA - Empresa Brasileira de Pesquisa agropecuária. Sistema Brasileiro de Classificação de Solos. 2.ed. Brasília: Embrapa Informação Tecnológica; Rio de Janeiro: Embrapa Solos, 2006. 306p.

Farias, M. F. de; Saad, J. C. C. Crescimento e qualidade de crisântemo cultivado em vaso sob ambiente protegido. Horticicultura Brasileira, v.23, p.740-742, 2005.

Ferreia, D. F. Sisvar: Um programa para análises e ensino de estatística. Revista Symposium, v.6, p.36-41, 2008.

Frizzone, J. A. Planejamento da irrigação com o uso de técnicas de otimização. Revista Brasileira de Agricultura Irrigada, v.1, p.24-49, 2007.

Genuchten, M. T. A closed form equation for predicting the hydraulic conductivity of insaturated soils. Soil Science Society of American Journal, v.41, p.892-898, 1980.

Ha, T. J.; Lee, M.; Park, C.; Pae, S.; Shim, K.; KO, J.; Shin, S.; Baek, I.; Park, K.; Identification and characterization of anthocyanins in yard-long beans (Vigna unguiculata ssp. sesquipedalis L.) by high-performance liquid chromatography with diode array detection and electrospray ionization/mass spectrometry (HPLC-DAD-ESI/MS) analysis. Journal of Agricultural and Food Chemistry, v.58, p.2571-2576, 2010.
Macedo, A. B. M.; Miranda, F. R. de; Gomes Filho, R. R.; Teixeira, A. S.; Cavalcante Júnior, J. A. H.; Araújo, H. F de. Desempenho de um sistema de irrigação automatizado através da tensão de água no solo. Revista Brasileira de Agricultura Irrigada, v.4, p.78-81, 2010.

Marouelli, W. A.; Giordano, L. B.; Oliveira, C. A. S.; Carrijo, O. A. Desenvolvimento e qualidade de ervilha sob diferentes tensões de água no solo. Pesquisa Agropecuária Brasileira, v.26, p.1041-1047, 1991.

Marouelli, W. A.; Silva, W. L. C.; Moretti, C. L. Resposta do tomateiro para processamento a tensões de água no solo, sob irrigação por gotejamento. Engenharia Agrícola, v.23, p.1-8, 2003a.

Marouelli, W. A.; Silva, W. L. C.; Moretti, C. L. Desenvolvimento de plantas, produção e qualidade de bulbos de alho sob condições de deficiência de água no solo. Horticultura Brasileira, v.20, p.470-473, 2003 b.

Oliveira, E. C. Manejo de irrigação da cultura do pepino japonês (Cucumis sativus L.) em ambiente protegido. Lavras: UFLA, 2009. 88p. Dissertação Mestrado

Pavani, L. C.; Lopes, A. S.; Pereira, G. T. Desenvolvimento da cultura do feijoeiro submetida a dois sistemas de manejo de irrigação e de cultivo. Acta Scientiarum Agronomy, v.31, p.453-459, 2009.

Sá, N. S. A. Cultivo do tomateiro (Licopersicon esculentum Mill.) em ambiente protegido sob diferentes tensões de água no solo. Lavras: UFLA, 2004. 71p. Dissertação Mestrado

Santos, S. R.; Pereira, G. M. Comportamento da alface tipo americana sob diferentes tensões da água no solo, em ambiente protegido. EngenhariaAgrícola, v.24, p.569-577, 2004.

Sarutayopha,T.; Nualsri, C.; Santipracha, Q.; Saereeprarat, V. Characterization and genetic relatedners among 37 yardlong bean an cowpea accessions based on morphological characters and RAPD analysis. Sangklanakarin Journal of Science and Tecchnology, v.29, p.591-600, 2007.

Silva, G. S. Galhas em caule de feijão-de-metro causadas por Meloydogine incógnita. Nematologia Brasileira, v.27, p.227228, 2003.

Taiz, L; Zeiger, E. Fisiologia vegetal. 4.ed. Porto Alegre: Artmed, 2009. 819p. 